\title{
Perceived Importance of Information: The Effects of Mentioning Information, Shared Information Bias, Ownership Bias, Reiteration, and Confirmation Bias
}

\author{
Lyn M. Van Swol \\ Northwestern University
}

\begin{abstract}
Participants were given information for and against the decriminalization of marijuana and discussed the issue in groups. Factors affecting rated importance of information after the group discussion were examined. Participants did not rate information that was mentioned during the discussion as more important than information not mentioned, and participants did not rate shared information they mentioned as more important than unshared information. Participants did rate shared information other group members mentioned as more important than unshared information others mentioned. Participants did not rate their own information as more important than other's information, and information that was repeated was not rated as more important. Participants did perceive information supporting their individual position as more important than information against their position, and this confirmation bias was lessened in groups containing an opinion minority. A comparison of minority and majority members in minority-containing groups found that minority members were more open to information than majority members.
\end{abstract}

KEYWORDS common information sampling bias, confirmation bias, minority, shared information

Groups are often used to make policy decisions about controversial issues because the diversity of opinions and information in a group is assumed to increase the consideration of many different viewpoints (Gruenfeld, Mannix, Williams, \& Neale, 1996; Surowiecki, 2004). However, research has found that group members often fail to discuss information unique to individual members (Wittenbaum \& Stasser, 1996) or consider information contrary to their opinions (Schulz-Hardt, Frey, Lüthgens, \&
Moscovici, 2000). One reason group members fail to consider unique information and information contrary to their opinion is that group members may weight this information as less important than information known to all group members and information supporting their

\section{$\overline{\text { Author's note }}$}

Address correspondence should be to Lyn M. Van Swol, 2240 Campus Drive, Evanston, IL 60208, USA [email: s-van2@northwestern.edu] 
opinion (Chernyshenko, Miner, Baumann, \& Sniezek, 2003; Greitemeyer \& Schulz-Hardt, 2003). This article examines how several factors influence the importance that people assign to information after discussing it in a group. Specifically, it is examined whether participants have an ownership bias toward rating information they know before the group discussion as more important than information learned from other group members, whether participants rate information that is mentioned and information that is repeated as more important, whether participants have a bias for shared information, and whether participants have a confirmation bias toward rating information supporting their opinion as more important than information against their opinion. Further, it is examined if the presence of an opinion minority reduces this confirmation bias.

\section{Bias for shared information}

Many researchers have found that groups discuss information that is known to and shared by all group members before the discussion more than information that is unshared and known to only one group member (e.g. Cruz, Boster, \& Rodriguez, 1997; Gigone \& Hastie, 1993, 1997; Gruenfeld et al., 1996; Henningsen \& Henningsen, 2003; Hollingshead, 1996a, 1996b; Larson, Christensen, Abbott, \& Franz, 1996; Larson, Foster-Fishman, \& Franz, 1998; Larson, Foster-Fishman, \& Keys, 1994; Savadori, Van Swol, \& Sniezek, 2001; Schittekatte \& Van Hiel, 1996; Stasser \& Stewart, 1992; Stasser, Stewart, \& Wittenbaum, 1995; Stasser, Taylor, \& Hanna, 1989; Stasser \& Titus, 1985, 1987; Stewart, 1998; Stewart, Billings \& Stasser, 1998; Stewart \& Stasser, 1995; Van Hiel \& Schittekate, 1998; Wittenbaum, 1998). Further, once mentioned, shared information tends to be repeated more than unshared information (Larson et al., 1994, 1996; Savadori et al., 2001; Stasser \& Stewart, 1992; Stasser et al., 1989, 1995; Wittenbaum, 1998). Wittenbaum and Stasser (1996) call this focus on shared information in groups the common information sampling bias. Researchers have examined many hypotheses for this bias. Statistically, information is more likely to be mentioned when it is shared because more group members can mention it (Stasser \& Titus, 1985; Tindale \& Kameda, 2000). At the group level, Gigone and Hastie $(1993,1997)$ have investigated how shared information has a larger impact on individuals' pre-group opinions, and therefore, is mentioned more often as group members defend their opinion during the course of the discussion and as these pre-group opinions influence the group's final decision.

Other researchers have investigated processes at the individual level, examining why individuals assign greater importance to shared information than unshared information (Chernyshenko et al., 2003; Greitemeyer \& Schulz-Hardt, 2003; Van Swol, Savadori, \& Sniezek, 2003). Specifically, Van Swol et al. (2003) examined how the ownership of information before the group discussion and the repetition of information can increase its importance to individuals. Greitemeyer and Schulz-Hardt (2003) examined how information supporting an individual's initial opinion is rated as more important. Chernyshenko et al. (2003) examined three characteristics that can increase the importance of information: whether it is common or unique, whether it is owned or not owned, and whether it is mentioned. This article examines how these factors affect how individuals rate the importance of information after a group discussion of a controversial issue.

\section{Common information sampling bias and mentioning of information}

Chernyshenko et al. (2003) predicted that information group members mention should be rated as more important than undiscussed information. They proposed that information increases in importance in a process called 'commitment enhancement' when it is mentioned because the act of mentioning a piece of information causes the information to increase in salience and validity. Further, information that is mentioned is often privately rehearsed before mentioning it and is more easily recalled. Undiscussed information, however, becomes less important because it becomes less salient and the fact that it is not discussed may be taken as a sign of the unimportance of the information 
(Chernyshenko et al., 2003). Therefore, I predict that information that is mentioned should be rated as more important than information that is not mentioned (Hypothesis 1).

However, once mentioned group members react to shared information more positively than unshared. Wittenbaum, Hubbell, and Zuckerman (1999) found that unshared information was not as highly regarded by members as shared information and that those who communicated more unshared information were viewed as less task competent than those who communicated more shared information. Shared information is socially validating (Wittenbaum \& Bowman, 2004) in that it confirms the accuracy and importance of one's information compared to others. Wittenbaum, et al. (1999) proposed that shared information enhances group members' evaluations of their knowledge and reinforces what members already know in a process they called mutual enhancement: 'a process whereby group members develop enhanced evaluations of each other's task capabilities when shared information is mentioned' (p. 5). Because shared information is mutually validating, group members react to the contributor of shared information with encouragement and positive evaluations, further enhancing the contributor's assessment of the information. However, the contributor of unshared information is often met with a lack of social validation. In addition to being mutually enhancing, shared information is familiar and easily validated (Parks \& Cowlin, 1996), increasing the likelihood participants will react positively to it when it is mentioned. Therefore, whereas shared and unshared information should be rated about equally when undiscussed, shared information should be rated as more important than unshared when it is discussed (Hypothesis 2).

\section{Ownership bias}

Chernyshenko et al. (2003) make a distinction between unshared information that group members know before the group discussion (own unshared) and unshared information they learn from other group members during the course of discussion (other unshared).
Van Swol et al. (2003) found that participants had an ownership bias toward rating information they received before the group discussion (shared and own unshared) as more valid and familiar than information not received (other unshared). This ownership bias could contribute to the common information sampling bias because shared information is owned by all members, and therefore, more highly valued by all group members. Chernyshenko et al. (2003) found that participants rated shared information and own unshared information that had been discussed as equally important, but rated both as more important than others' unshared information. They stated: 'The simple distinction between common (shared) and unique (unshared) information is insufficient for understanding individual members' judgment processes' (p. 22). Chernyshenko et al. (2003) speculated that group members may not always hear or process other's information because they are busy concentrating on what they themselves are going to contribute to the group discussion. Further, even if the other's unshared information is heard, people tend to believe themselves more than others (Alicke, Klotz, Breitenbecher, Yurak, \& Vrendenburg, 1995), value that which has been given to them more highly than that given to another person (Kahneman, Knetsch, \& Thaler, 1991), and value their own judgment and information more than that of another (Van Swol \& Sniezek, 2002; Yaniv \& Kleinberger, 2000). Therefore, I hypothesize participants will have an ownership bias, and group members will rate information they learned before the group discussion (shared and own unshared) as more important than information only other group members knew (other unshared) before the discussion (Hypothesis 3).

\section{Reiteration}

Van Swol et al. (2003) examined how the repetition of shared information can prevent groups from uncovering hidden profiles. Research examining the bias for shared information in groups has often used a hidden profile (Brodbeck, Kerschreiter, Mojzisch, Frey, \& Schulz-Hardt, 2002; Dennis, 1996; Hollingshead, 1996a; 
Savadori et al., 2001; Stasser \& Stewart, 1992; Stasser et al., 1995; Stasser \& Titus, 1985). In a hidden profile, the majority of information supports one alternative (superior alternative). However, the information is distributed such that most of the shared information supports the inferior alternative(s), and most of the unshared information supports the superior alternative. Because each group member receives all the shared information but only part of the unshared information, individuals tend to prefer an inferior alternative before meeting in the group. In order to uncover the hidden superior alternative, it is necessary, but not always sufficient, for the group to discuss the majority of the unshared information. However, groups generally fail to adequately discuss unshared information and uncover hidden profiles.

Van Swol et al. (2003) had individuals make an initial decision in a hidden profile task after receiving a biased individual profile of information. After making this initial decision, Van Swol et al. (2003) gave the participants the rest of the information. Therefore, individuals had access to all the information necessary to detect the superior alternative and uncover the hidden profile. However, in the repetition condition, participants received the shared information two more times after their initial decision. Therefore, participants received the rest of the unshared information in addition to two more exposures to the shared information. In the non-repetition condition, participants received only the rest of the unshared information. Therefore, in this condition, participants had one exposure to each piece of information. Van Swol et al. (2003) found that participants were much more likely to uncover the hidden profile when the shared information was not repeated, even though participants in both conditions had access to the information needed to uncover the hidden profile. They attributed this result to participants assigning more validity and importance to information that was repeated. They posited that one reason groups weight shared information more heavily and fail to uncover hidden profiles is that shared information is repeated more often.

Other researchers have investigated this 'reiteration effect' (Hertwig, Gigerenzer, \&
Hoffrage, 1997) or 'validity effect' (Arkes, 1993; Boehm, 1994). Hasher, Goldstein, and Toppino (1977) verified that repetition of information increases the perception that the information is true, valid, and reliable. Repetition may be used as a heuristic to the truthfulness of a statement when there are no other indicators of the statement's validity, and this effect of repetition is often automatic and uses few cognitive resources (Alba, Chromiak, Hasher, \& Attig, 1980; Hasher \& Chromiak, 1977; Hasher et al., 1977; Hasher \& Zacks, 1984). Therefore, I hypothesize that information that is repeated during the group discussion will be rated as more important than information that is not repeated (Hypothesis 4 ).

\section{Confirmation bias}

Much research has found that people have a preference for information that confirms their initial opinion compared to information that disconfirms it (for review see, Frey, 1986). This preference is referred to as the confirmation bias. For example, Russo, Medvec, and Meloy (1996) found that participants distorted new information to favor their preferred alternative. Lord, Ross, and Lepper (1979) examined how people process information that confirmed or disconfirmed their opinion on social issues. People rated confirming information as more convincing and were more critical of disconfirming information. Schulz-Hardt et al. (2000) found that groups displayed a confirmation bias; groups requested more information that supported the initial group opinion than information contrary to the group opinion.

Greitemeyer and Schulz-Hardt (2003) examined how the confirmation bias affects how information is evaluated in a hidden profile. Because the majority of individuals approach the group discussion supporting the inferior alternative, Greitemeyer and Schulz-Hardt (2003) hypothesized that the failure of groups to uncover hidden profiles could be the result of the individual level process of group members evaluating information supporting their opinion more favorably than information not supporting their opinion. Greitemeyer and Schulz-Hardt (2003) 
simulated a group hidden profile by giving participants an information profile similar to the pre-group information participants receive before discussing a hidden profile in a group. Therefore, individuals only received part of the 'unshared' information and generally chose the inferior choice. After making their first decision, participants individually read a transcript of a group discussion in which participants received the full set of information. Despite learning all the information so that participants had more information disconfirming their initial decision than confirming it, most participants maintained their initial, inferior choice. Greitemeyer and Schulz-Hardt (2003) found that participants rated information supporting their initial opinion as more important and that this confirmation bias mediated the failure of individuals to uncover hidden profiles. Therefore, participants were subject to the confirmation bias and were unable to uncover the hidden profile after their initial choice, even though they were subsequently given all the information necessary to uncover the superior alternative, because they evaluated information supporting their choice as more important than information disconfirming their choice. Consistent with this research I hypothesize that information confirming a group member's opinion will be rated as more important than information disconfirming the opinion (Hypothesis 5a).

However, Greitemeyer and Schulz-Hardt (2003) did not use real interacting groups, and they stressed that investigating biased evaluation of discussion content in real group studies not only seems necessary ... but could also lead to the identification of conditions under which group members are better able to conduct an unbiased assessment of the information available to them' (p. 337). In the present study, I examine how participants rate the importance of confirming and disconfirming information discussed in real, interacting groups. However, I also examine how groups containing an opinion minority may be 'better able to conduct an unbiased assessment of the information available to them' (p. 337) than groups that are in consensus.
Research examining minority influence has suggested that different processes may motivate influence from a minority and majority in a group (for review see, Meyers, Brashers, \& Hanner, 2000; Wood, Lundgren, Ouellette, Busceme, \& Blackstone, 1994). Specifically, people may publicly conform to a majority to avoid reprimand or ridicule, whereas minority influence may be more sincere and private (Moscovici, 1980). Additionally, a minority opinion may facilitate divergent thinking in the group causing group members to consider the issue from multiple angles, rather than just comparing their view with the majority opinion (De Dreu \& De Vries, 1996; Nemeth, 1986; Nemeth \& Rogers, 1996). Brodbeck et al. (2002, p. 39) said that, 'minority influence facilitates open-mindedness towards alternative solutions' so an issue is analyzed 'broader and more critically'. Therefore, a group containing a minority may be more open to new information than groups that are in consensus without exposure to a minority opinion.

Schulz-Hardt et al. (2000) found that when groups contained an opinion minority they were less subject to a confirmation bias when requesting additional information than homogeneous groups. They hypothesized that the presence of opinion minorities may have encouraged divergent thinking and the consideration of more conflicting information. Schulz-Hardt, Jochims, and Frey (2002) also found that groups containing members with heterogeneous opinions were less likely to engage in biased information seeking than homogeneous groups. They found that heterogeneous groups had lower confidence in their decision. They reasoned that the presence of conflicting preferences could make group members feel that they did not accurately evaluate the information, thus lowering their confidence. This lower confidence could make group members more open to critical examination and conflicting information, as group members are uncertain about the correctness of their position. Also, Propp (1997) found that groups with conflicting pre-discussion preferences accepted significantly more information compared to groups in 
consensus. Based on this research I hypothesize that groups containing a minority opinion will be more open to information, so that information that is against a group member's opinion will be rated as more important in groups containing a minority than in groups in which everyone is in consensus (Hypothesis 5b).

Although previous research (Chernyshenko et al., 2003; Greitemeyer and Schulz-Hardt, 2003; Van Swol et al., 2003) has examined the ideas discussed above separately, this is the first study to examine all these individual level processes together. Further, Greitemeyer and Schulz-Hardt (2003) examined the effects of the confirmation bias on shared information and Van Swol et al. (2003) examined the reiteration effect on shared information using individuals and not interacting groups. Also, Van Swol et al. (2003) examined the ownership bias in groups but did not track which information was mentioned and not mentioned. The current study builds on that previous research by examining these individual level processes within interacting groups and then tracking the amount of discussion of each piece of information and how discussing information affects its rated importance. However, Chernyshenko et al. (2003) did track the discussion of information against its rated importance, but did not compare self-contributed shared information to other-contributed shared information, which I do in this article. Finally, this article adds to previous research by using a non-fictional real life task. Previous research examining shared information has often used fictitious tasks. For example, Chernyshenko et al. (2003) and Van Swol et al. (2003) had participants make decisions about a fictitious pharmaceutical company. However, this study uses real information about a task that participants are likely to have a formed opinion about before the experiment. Because I use a task in which participants are likely to be on one side of the issue or another, I am also able to examine the role of opinion minorities and the rating of shared information. Previous research examining the bias for shared information has seldom examined the role of minority and majority opinions in the process of information exchange.

\section{Method}

\section{Participants}

Participants $(n=129)$ were undergraduates from a communication studies department at a private midwestern university completing the study as part of a class requirement. Participants met in three person groups $(n=43)$. In each group, the range of opinions toward the decriminalization of marijuana was random. Twenty-one of the groups had a minority and majority with one or two members for the decriminalization of marijuana and the remaining member(s) against. These were classified as majority/minority groups. In 10 groups, all group members shared the same opinion toward the decriminalization of marijuana. These were classified as consensus groups. The remaining 12 groups, the neutralcontaining groups, contained one member who rated themselves as neutral on the issue while the remaining members were either for or against decriminalization.

\section{Procedure}

After informed consent, participants read a paragraph describing the issue of the decriminalization of marijuana. Then participants rated their opinion on the issue prior to group discussion on a scale from 1-9: 1- Ioppose all measures and tendencies toward the decriminalization of marijuana; 5 - I am neutral on the issue; to 9 I support the decriminalization of marijuana. From this pre-group opinion, groups were classified as majority/minority group, consensus group, or neutral-containing group. Pilot testing had found that participants $(n=16)$ rated the topic of the decriminalization of marijuana as moderately controversial $(M=5.63, S D=1.15)$ on a scale from 1 - Not at all controversial to 7 - Very controversial) and that $63 \%$ of the pilot study participants were pro-decriminalization and $37 \%$ were against.

After rating their individual opinion, participants were given 16 pieces of information about the decriminalization of marijuana. Eight of the pieces of information were given to all three group members. This is the shared information. The other eight pieces of information were different for each group member. This is the unshared 
information. What information was used as shared and unshared was counterbalanced to prevent a confound between the type of information and the content of the information. All the information had been rated by participants in the pilot study for valence and importance. Based on the ratings from the pilot study, four sets of eight pieces of information were created that were fairly equivalent in terms of the ratings. Half of the information, both shared and unshared, was pro-decriminalization, and half was against decriminalization. Examples of pro-decriminalization of marijuana information included: 'Marijuana was decriminalized in Holland in 1976. From 1976 to 1984, there was no increase in the number of Dutch marijuana smokers. (The Nation, September 20, 1999) ' and 'A study by the Center for Substance Abuse Research has found since the passing of an initiative in California in 1996 allowing the use of marijuana for medicinal purposes, there has not been a significant increase in marijuana use'. Examples of anti-decriminalization of marijuana information are:

The Alaska Supreme Court ruled in 1975 that the state could not interfere with a person's possession of marijuana in his home for personal use. According to a 1988 University of Alaska study, the state's 12 to 17 -year-olds used marijuana at more than twice the national average for their age group. Alaska residents voted in 1990 to recriminalize possession of marijuana

and 'Marijuana has been shown to degrade short-term memory, concentration, judgment, and coordination at complex tasks, including driving'. Participants were asked to read through their information before meeting in a group to discuss it.

After reading the information, participants met in three person groups to discuss the issue. Groups were instructed to come to a group consensus on the issue and were given a sheet to rate the group's opinion on the same 1-9 scale participants had filled out before meeting in the group. Participants were also told:

Everyone in the group was given 16 pieces of information about the issue before meeting in a group. Some of the pieces of information they received are identical to some of the information you received. However, some of the information they received is different from the information you received. Therefore, another group member may have information that you do not have. You will have up to 30 minutes to discuss the information as a group.

The groups were videotaped. The average group discussed the issue a little more than 12 minutes. After informing the experimenter that the group had reached consensus, group members were moved to separate rooms and asked to rate each of the 32 pieces of information on a scale from 1-10: 1 - Not important, 5 - Somewhat important, and 10 - Very important.

The videos of the group discussions were transcribed word for word by an experimental assistant so that the discussions could be coded. There were two stages to the coding. Two coders, who were uninvolved in the transcription of the discussions, coded the discussions into idea units. The coders were instructed to bracket off each part of the discussion that constituted one idea. An idea unit could constitute a sentence, part of a sentence, several sentences, or even one word. Guetzkow's U (1950) was used as a measure of unitizing disagreement. Guetzkow's $\mathrm{U}$ is computed by subtracting the amount of idea units coded by the second coder from the amount coded by the first coder and dividing this difference by the total amount of idea units coded by both of the coders across all discussions. The unitizing reliability between the two coders was good, $U=.005$. Any discrepancies between the two coders were settled by a master coder. The transcripts that were bracketed into idea units were then coded by two new coders, who coded the transcripts for discussion of information from the information sheets given to participants. Their reliability was good (Cohen's kappa $=.73, S E=.02)$. Again, a master coder settled any discrepancies and designated each piece of information as common or unique (own or other) based on its use in the experiment.

\section{Results}

This study uses Hierarchical Linear Modeling (HLM) software version 5.5 for some of the analyses because the individuals were nested within groups. Individual level one predictor 
variables were group mean centered and group level two predictor variables were grand mean centered. Also, when variance was close to zero $(p>.50)$ effects were modeled as fixed (Bryk \& Raudenbush, 1992; Nezlek, 2001).

HLM examined differences between groups in the rating of importance of shared and unshared information. There was no difference between groups on how participants rated shared information $\left(\gamma_{01}=-.007, S E=0.03, t(41)=0.28\right.$, $p=.78)$; or unshared information $\left(\gamma_{01}=.024\right.$, $S E=0.02, t(41)=1.018, p=.32)$. Unshared information was further divided into unshared information the participant had been given (own) and unshared information other group members had. There was no difference between groups on how participants rated their own unshared information $\left(\gamma_{01}=.014, S E=0.02, t(41)\right.$ $=0.57, p=.57)$; or other's unshared information $\left(\gamma_{01}=.029, S E=0.03, t(41)=1.11, p=.27\right)$. For aggregate group means, see Table 1.

The mean aggregate group rating of shared and unshared information was compared in a repeated measures analysis of variance. There was no difference between the ratings of shared $(M=6.42, S D=0.67)$ and unshared information $(M=6.50, S D=0.62)(F(1,40)=$ $\left.1.26, \eta^{2}=0.03, p=.27\right)$, nor was there an interaction with type of group $(F(2,40)=0.34$, $\left.\eta^{2}=0.02, p=.72\right)$. Therefore, contrary to what the common information sampling bias would predict, shared information was not rated as more important. However, this was a test of all information, both discussed and undiscussed; A test of just the information discussed in the group is next.
I compared how participants rated information that was mentioned during the discussion to information not mentioned. A between-groups repeated measures analysis of variance was conducted on the group mean to compare shared information that was mentioned to shared information not mentioned. A similar analysis was conducted for unshared information and own information. For all three types of information (shared, unshared, and own), there was no difference between the rating of importance of mentioned information and non-mentioned information $\left(F(1,40)=1.13, \eta^{2}=0.03, p=.29\right.$; $F(1,40)=1.77, \eta^{2}=0.04, p=.19 ; F(1,40)=0.00$, $\eta^{2}=0.00, p=.96$, respectively). Further, there was no effect of type of group (consensus, majority/minority, neutral) for the three types of information $\left(F(2,40)=0.60, \eta^{2}=0.03\right.$, $p=.56 ; F(2,40)=0.34, \eta^{2}=0.02, p=.71 ; F(2,40)$ $=0.54, \eta^{2}=0.03, p=.59$, respectively). For means see Table 2. It was analyzed if participants rated shared information they mentioned higher than shared information mentioned by another person during discussion $(M=7.31, S D=1.23)$. A repeated measures analysis of variance between groups was not significant $(F(1,40)=1.62$, $\left.\eta^{2}=0.04, p=.21\right)$, nor was there an effect of group $\left(F(2,40)=0.29, \eta^{2}=0.01, p=.75\right)$. However, it was analyzed if participants rated shared information mentioned only by another person as more important than shared information not mentioned at all. There was a significant effect $\left(F(1,40)=6.99, \eta^{2}=0.15, p=.01\right)$. Shared information mentioned by another person was rated as more important than shared information not mentioned, but there was no interaction

Table 1. Mean rating of importance of information between groups

\begin{tabular}{|c|c|c|c|c|c|c|}
\hline & \multicolumn{2}{|c|}{ Minority/majority } & \multicolumn{2}{|c|}{ Consensus } & \multicolumn{2}{|c|}{ Neutral-containing } \\
\hline & $M$ & $S D$ & $M$ & $S D$ & $M$ & $S D$ \\
\hline Shared & 6.30 & 0.63 & 6.63 & 0.55 & 6.44 & 0.82 \\
\hline Unshared & 6.35 & 0.66 & 6.68 & 0.31 & 6.64 & 0.70 \\
\hline Own unshared & 6.48 & 0.62 & 6.73 & 0.28 & 6.66 & 0.78 \\
\hline Other unshared & 6.28 & 0.74 & 6.65 & 0.45 & 6.62 & 0.70 \\
\hline For individual opinion & 6.93 & 0.69 & 7.85 & 0.64 & 7.14 & 0.85 \\
\hline Against individual opinion & 6.02 & 0.69 & 5.52 & 0.43 & 6.09 & 1.17 \\
\hline For group opinion & 6.66 & 0.71 & 7.85 & 0.64 & 7.04 & 0.49 \\
\hline Against group opinion & 6.31 & 0.72 & 5.52 & 0.43 & 6.34 & 1.02 \\
\hline
\end{tabular}


Table 2. Mean rating of importance of information mentioned and not mentioned

\begin{tabular}{lcccccccccc}
\hline & \multicolumn{2}{c}{ Shared } & & \multicolumn{3}{c}{ Unshared } & & \multicolumn{2}{c}{$\begin{array}{c}\text { Unshared- } \\
\text { own }\end{array}$} \\
\cline { 2 - 3 } & $M$ & $S D$ & & $M$ & $S D$ & & $M$ & $S D$ \\
\hline Mentioned & 6.87 & 1.54 & & 6.13 & 1.87 & & 6.59 & 1.14 \\
Not mentioned & 6.65 & 1.07 & & 6.56 & 0.60 & & 6.63 & 0.66 \\
\hline
\end{tabular}

with type of group $\left(F(2,40)=0.22, \eta^{2}=0.01\right.$, $p=.80)$. In conclusion, contrary to Hypothesis 1 , participants did not rate information they mentioned as more important than information not mentioned. However, in partial support of Hypothesis 1, shared information that another person mentioned was rated as more important than shared information not discussed.

To test Hypothesis 2, a between-groups repeated measures analysis of variance compared shared information mentioned versus unshared information mentioned. There was a marginal effect of information $\left(F(1,40)=3.19, \eta^{2}=0.07\right.$, $p=.08)$, but no interaction with type of group $\left(F(2,40)=0.03, \eta^{2}=0.00, p=.97\right)$. Shared information that was mentioned was rated as more important than the unshared information mentioned. Shared information not mentioned was compared to unshared information not mentioned in a repeated measures analysis of variance between groups. There was no significant difference between shared and unshared information not mentioned $\left(F(1,40)=0.00, \eta^{2}=0.00, p=.98\right)$, nor an interaction with type of group $(F(2,40)=$ $\left.1.54, \eta^{2}=0.07, p=.23\right)$. Further, it was analyzed how participants rated shared information only another mentioned versus unshared information mentioned by another. There was a significant effect of information, shared information another mentioned $(M=7.31, S D=1.23)$ was rated higher than unshared information mentioned by another $(M=6.36, S D=$ 1.36) $\left(F(1,40)=11.96, \eta^{2}=0.23, p<.001\right)$. Hypothesis 2 predicted that for information that is mentioned, shared information should be rated as more important than unshared. For the mentioning of participants' own information, this hypothesis was only marginally significant.
However, shared information was rated as more important than unshared for information others mentioned. Therefore, Hypothesis 2 was partially supported.

To test Hypothesis 3, the mean aggregate group rating of own information (shared and own unshared) and other information was compared in a repeated measures analysis of variance. There was no difference between the ratings of own $(M=6.51, S D=0.58)$ and other's information $(M=6.46, S D=0.68),(F(1,40)$ $\left.=0.11, \eta^{2}=0.00, p=.74\right)$, nor was there an interaction with type of group $(F(2,40)=0.58$, $\left.\eta^{2}=0.03, p=.57\right)$. This fails to support the ownership bias, Hypothesis 3.

To test Hypothesis 4, I analyzed how the repetition of information affected its rated importance. It was examined if participants rated shared information that was repeated $(M=6.95, S D=1.41)$ higher than shared information not mentioned. The same analysis was conducted for own unshared information and for other's unshared. For all three types of information (shared, own unshared, and other's unshared), there was not a significant difference between repeated and not mentioned information $\left(F(1,16)=2.67, \eta^{2}=0.14, p=.12\right.$; $F(1,9)=0.16, \eta^{2}=0.02, p=.70 ; F(1,10)=0.77$, $\eta^{2}=0.07, p=.40$, respectively). Nor was there an effect of type of group $\left(F(2,16)=1.13, \eta^{2}=\right.$ $0.12, p=.35 ; F(2,9)=2.12, \eta^{2}=0.32, p=.18$; $F(2,10)=1.54, \eta^{2}=0.24, p=.26$, respectively) . Although, there was an interesting trend for own unshared information, in consensus groups own unshared information that was repeated was rated higher $(M=8.50, S D=0.71)$ than in minority/majority groups $(M=6.70, S D=1.86)$ or neutral-containing groups $(M=5.20, S D=2.59)$. In conclusion, no support was found for Hypothesis 4, that the repetition of information would increase its perceived importance.

The next set of analyses tested the confirmation bias. Neutral-containing groups were excluded from the following analysis. An analysis of variance on the group mean found that participants in consensus groups rated information in support of their pre-group opinion as more important than participants in minority/ majority groups $\left(F(1,29)=12.75, \eta^{2}=0.31\right.$, 
$p<.001)$. Also, the mean rating of information that was against the individual's pre-group opinion was examined. Participants in consensus groups rated information against their pre-group opinion as less important than participants in minority/ majority groups $\left(F(1,29)=4.46, \eta^{2}=0.13, p<.05\right)$. A between-groups repeated measures analysis of variance comparing information for and against the individual opinion was conducted using the group aggregate. There was a significant effect of information $\left(F(1,29)=135.04, \eta^{2}=0.82\right.$, $p<.0001)$. Participants were much more likely to rate information for their individual opinion as more important than information against it. This supports Hypothesis 5a. However, this was qualified by a significant interaction with group $\left(F(1,29)=26.09, \eta^{2}=0.47, p<.0001\right)$. Each group was analyzed separately, and it was found that individuals in minority/majority groups and consensus groups $(F(1,20)=42.70$, $\eta^{2}=0.68, p<.0001 ; F(1,9)=68.32, \eta^{2}=0.88$, $p<.0001$, respectively) both rated information for their individual opinion as more important than information against their opinion, but the effect size for consensus groups was larger. Therefore, participants in consensus groups were more likely to have a confirmation bias toward information supporting their opinion than participants in minority/majority groups, in support of Hypothesis 5b.

Analyses also examined the presence of a confirmation bias toward the group opinion. Five groups whose position was neutral were excluded from the following analysis. An analysis of variance between groups was conducted on how individuals rated information for the group position. There was a significant effect $(F(2,35)=$ $\left.11.05, \eta^{2}=0.39, p<.0001\right)$. Post hoc Scheffé tests revealed that consensus groups were significantly more likely to rate information for the group's position as more important than either the minority/majority groups (mean difference $=$ $1.19, S E=0.25, p<.0001)$ or neutral-containing groups (mean difference $=0.81, S E=0.29, p<.05$ ). However, minority/majority groups and neutralcontaining groups did not significantly differ ( mean difference $=0.38, S E=0.25, p=.33$ ). A similar analysis was conducted on rated importance of information against the group opinion.
There was a significant effect $(F(2,35)=4.21$, $\left.\eta^{2}=0.19, p<.05\right)$. Post hoc Scheffé tests revealed that consensus groups rated information against the group opinion as significantly less important than minority/majority groups (mean difference $=0.79, S E=0.30, p<.05)$. However, consensus groups did not significantly differ from neutral-containing groups (mean difference $=0.83, S E=0.34, p=.06$ ) and minority $/$ majority groups and neutral-containing groups did not significantly differ ( mean difference $=0.04$, $S E=0.30, p=.99$ ). A repeated measures analysis of variance comparing information for and against the group opinion was conducted using the group aggregate. There was a significant effect of information $\left(F(1,35)=70.50, \eta^{2}=0.67\right.$, $p<.0001)$. Participants were much more likely to rate information for the group opinion as more important than information against it. However, this was qualified by a significant interaction with group $\left(F(2,35)=20.52, \eta^{2}=0.54, p<.0001\right)$. Each group was analyzed separately, and it was found that individuals in minority/majority groups $\left(F(1,35)=3.83, \eta^{2}=0.18, p=.07\right)$ did not rate information for and against the group position significantly different, but participants in consensus groups and neutral-containing groups $\operatorname{did}\left(F(2,35)=68.32, \eta^{2}=0.88, p<.0001, F(2,35)=\right.$ $\left.8.66, \eta^{2}=0.49, p<.05\right)$. In conclusion, consensus groups had more of a confirmation bias towards information supporting the group's opinion.

\section{Minority/majority groups}

In the minority-containing groups, there were six groups in which the minority opinion prevailed as the group opinion. Half of these groups were pro-decriminalization and half were against. HLM analysis was conducted to examine whether or not the minority prevailed as a level 2 group variable and type of member (minority or majority) as a level 1 individual variable. HLM analysis showed that minorities $(M=6.74, S D=0.71)$ rated shared information as more important than majority members $(M=6.08, S D=1.04)\left(\gamma_{10}=-.33, S E=0.119, t(19)\right.$ $=-3.07, p<.01$; and there was no interaction with whether the minority prevailed $\left(\gamma_{11}=.27\right.$, $S E=0.20, t(19)=1.32, p=.20)$. For unshared information that was given to participants (own 
unshared $)$, minorities $(M=6.71, S D=1.14)$ did not significantly differ from majorities $(M=6.37, S D=1.02)\left(\gamma_{10}=-.17, S E=0.14, t(19)=\right.$ $-1.16, p=.26)$, and there was no interaction with whether or not the minority opinion prevailed as the group opinion $\left(\gamma_{11}=-.09, S E=0.32, t(19)=\right.$ $-0.27, p=.79)$. For other's unshared information, effects were modeled as fixed for the slope due to very low variance $(p>.50)$. Groups in which the minority prevailed $(M=5.81, S D=$ 1.29) rated other's unshared information as marginally less important than groups in which the majority prevailed $(M=6.47, S D=1.00)$, $\left(\gamma_{01}=-.65, S E=0.33, t(19)=-1.95, p=.07\right)$. Further, minorities $(M=6.62, S D=1.00)$ rated other's unshared information as marginally more important than majorities $\operatorname{did}(M=6.11$, $S D=1.14),\left(\gamma_{10}=-.25, S E=0.13, t(59)=-1.88\right.$, $p=.07)$, but there was no interaction with whether or not the minority opinion prevailed as the group opinion $\left(\gamma_{11}=.17, S E=0.30, t(59)=\right.$ $0.57, p=.57)$.

HLM analysis examined the rating of importance of information supporting the individual participant's opinion. Individuals in groups in which the minority prevailed $(M=6.40$, $S D=1.20)$ rated information for their individual position as less important than participants in groups in which the majority prevailed $(M=7.14$, $S D=0.97)\left(\gamma_{01}=-.75, S E=0.29, t(19)=-2.54\right.$, $p<.05)$. There was no significant effect of type of member $\left(\gamma_{10}=-.22, S E=0.14, t(19)=-1.59\right.$, $p=.13$ ), or interaction with whether or not the minority opinion prevailed as the group opinion $\left(\gamma_{11}=-.10, S E=0.30, t(19)=-0.34, p=.74\right)$. For information against the individual's opinion, effects for the slope were modeled as fixed because variance was close to zero. There was no effect of whether or not the minority opinion prevailed as the group opinion $\left(\gamma_{01}=-.41\right.$, $S E=0.33, t(19)=-1.24, p=.23)$. Minorities $(M=6.37, S D=1.06)$ rated information against their individual opinion as more important than majority members $(M=5.85, S D=1.06)$ $\left(\gamma_{10}=-.26, S E=0.13, t(59)=-1.97, p=.05\right)$, and there was no interaction with whether or not the minority opinion prevailed as the group opinion $\left(\gamma_{11}=.34, S E=0.29, t(59)=1.17, p=.25\right)$.
A repeated measures analysis of variance examined how minority and majority members rated shared information that they mentioned during the discussion versus shared information that was not mentioned. There was a significant interaction $\left(F(1,26)=5.79, \eta^{2}=0.18\right.$, $p<.05)$. Minorities rated shared information they mentioned $(M=6.17, S D=2.50)$ lower than information they did not mention $(M=7.30$, $S D=1.41)$, whereas majority members rated shared information they mentioned as higher $(M=7.02, S D=1.51)$ than shared information they did not mention $(M=6.43, S D=1.18)$. A similar analysis was conducted on participants' own information. There was a marginally significant interaction $\left(F(1,35)=3.03, \eta^{2}=0.08, p=.09\right)$. Minorities rated their own information that they mentioned $(M=6.24, S D=1.57)$ lower than their own information that they did not mention $(M=6.92, S D=0.93)$, whereas majority members rated their own information they mentioned as higher $(M=6.61, S D=1.25)$ than information they did not mention $(M=6.47, S D=0.79)$. For review of the major results, see Table 3 .

\section{Discussion}

In sum, participants did not rate information they mentioned as more important than information they did not mention, contrary to Hypothesis 1. However, Hypothesis 1 did receive some support in that participants rated shared information another person mentioned as more important than shared information not mentioned. Hypothesis 2 predicted that shared information discussed would be rated as more important than unshared information discussed. This bias for shared information was marginally significant for information participants themselves mentioned, but it was significant for information others mentioned. Therefore, Hypothesis 2 received partial support. For information not mentioned, there was no bias toward rating shared information as more important than unshared information. Further, there were no differences between the types of groups in the rating of shared and unshared information. Participants did not have 
Table 3. Highlight of important significant results

\begin{tabular}{|c|c|}
\hline Description & ANOVA statistics \\
\hline $\begin{array}{l}\text { Shared information mentioned only by another person rated as more } \\
\text { important than shared information not mentioned at all. }\end{array}$ & $F(1,40)=6.99, \eta^{2}=0.15, p=.01$ \\
\hline $\begin{array}{l}\text { Shared information that was mentioned rated as marginally more } \\
\text { important than the unshared information mentioned. }\end{array}$ & $F(1,40)=3.19, \eta^{2}=0.07, p=.08$ \\
\hline $\begin{array}{l}\text { Shared information only another mentioned rated more important } \\
\text { than unshared information mentioned only by another. }\end{array}$ & $F(1,40)=11.96, \eta^{2}=0.23, p<.001$ \\
\hline $\begin{array}{l}\text { Participants in consensus groups rated information in support of } \\
\text { pre-group opinion as more important than participants in minority/ } \\
\text { majority groups. }\end{array}$ & $F(1,29)=12.75, \eta^{2}=0.31, p<.001$ \\
\hline $\begin{array}{l}\text { Participants in consensus groups rated information against pre-group } \\
\text { opinion as less important than participants in minority/majority groups. }\end{array}$ & $F(1,29)=4.46, \eta^{2}=0.13, p<.05$ \\
\hline
\end{tabular}

an ownership bias toward rating information they received before the group discussion as more important than other's unshared information, so Hypothesis 3 was not supported. Further, participants did not rate information that was repeated as more important, so Hypothesis 4 was not supported. In support of Hypothesis $5 \mathrm{a}$, participants did have a confirmation bias toward information that supported their opinion, but in support of Hypothesis 5b, the presence of an opinion minority in the group lessened this confirmation bias. Groups also had a confirmation bias toward information supporting the group opinion. Finally, within minority-containing groups, minority and majority members were compared. Minorities tended to rate information as more important than majorities, with the exception of their own unshared. Also, minorities rated information against their opinion as more important than majorities. Further, minorities rated shared information they mentioned as less important than shared information they did not mention.

\section{Bias for shared information}

Chernyshenko et al. (2003) stated that the bias for shared information does not occur for information that is not discussed in the group. My results support this; For the information that was not discussed, shared and unshared information was rated about equally important. However, for the information that was discussed, it was predicted that shared information would be rated as more important than unshared due to mutual enhancement and the positive response that shared information would receive when mentioned. This bias for shared information was only significant for information that other group members mentioned, but for information group members themselves mentioned, it was only marginally significant. This difference was mainly due to the shared information that others mentioned being rated higher than shared information members mentioned themselves. It is possible that mutual enhancement is stronger for shared information another person mentions than shared information a group member themselves mentions. When a group member mentions a piece of shared information, they may or may not receive validation from other group members. Therefore, the group member may not always realize that the information is shared among the group. However, when a group member hears another group member mention a piece of shared information, they know that this piece of information matches their own information and validates what they know. So, even if the group member remains silent when they hear another member mention a piece of shared information, hearing the shared information mentioned is still validating. However, having shared information validated when one mentions it requires another group member to engage in some verbal or nonverbal action affirming the information. Chernyshenko et al. (2003) 
had predicted that 'self-contributed common (shared) cues would be more important' than other-contributed shared cues (p. 23), but they were unable to test this in their study. However, my results suggest the opposite. The idea that hearing shared information mentioned by others is more mutually enhancing and validating than mentioning the shared information oneself is an interesting idea that deserves further testing.

\section{Ownership bias}

Contrary to previous research (Chernyshenko et al., 2003; Van Swol et al., 2003), I found no support for the ownership bias. Participants did not rate information they received before the group discussion as more important than other's unshared information. The information given to participants was all factual. None of the information was fabricated, and often sources for the piece of information were given. For example, a piece of information would be attributed to the 'Office of National Drug Control Policy' or a 'RAND institute study'. One reason participants may have an ownership bias toward their information is that they can verify their own information, but may question the validity of information received from another person. However, because all the information participants received in this experiment cited the source of the information, they may have been less likely to doubt the validity of new information. Therefore, when participants were rating the information after the group discussion, all the information probably appeared true and valid, and it may not have mattered whether the participants had been given the information before the group discussion or not. Results in support of the confirmation bias suggest that it was much more important to participants whether the information supported their opinion than whether it was given to them by the experimenter. Because the topic was one in which most participants came to the experiment with pre-existing viewpoints, they may have been open to any information, as long as it supported their views.

However, the ownership bias could play a role in other processes underlying the bias for shared information. The ownership bias could underlie some of the effects of mutual enhancement. Because participants have bias toward their own information, they may react positively toward another group member who mentions their information (Wittenbaum, et al., 1999).

\section{Reiteration effect}

Contrary to Hypothesis 4, information that was repeated was not rated as more important. One problem is that there was not a lot of repetition of information. Only about a quarter of the group members repeated any of the information, so the sample size was small. For shared information, there was a trend toward rating repeated information as more important, but it failed to reach significance. Further, in all but a few cases, the participant only repeated the piece of information once. Van Swol et al. (2003) found that the repetition of shared information prevented individuals from uncovering hidden profiles, but participants in their repetition condition had all the shared information repeated twice. Further, in Van Swol et al. (2003) participants did not engage in a group discussion, but simply received the information in written format. Therefore, the repetition was more salient in Van Swol et al. (2003). In the present experiment, there might be considerable discussion before the information was repeated.

Also, previous research examining the effects of repetition has used information in which participants have few indicators of the information's validity (Alba et al., 1980; Van Swol et al., 2003). Amount of repetition may be the only clue participants can use to determine if a piece of information is important or valid. However, the information in this experiment was factual and often gave participants information about the piece of information's source. Therefore, participants had other clues, besides the amount of repetition, on which to judge a piece of information, and it is likely that these other clues were more salient. There may not have been any effect of repetition because participants only use repetition to judge a piece of information when other indicators are not available. 


\section{Confirmation bias}

In support of Hypothesis $5 \mathrm{a}$ and much previous research, participants rated information supporting their position as more important than information contrary to their position. Greitemeyer and Schulz-Hardt (2003) stressed the importance of identifying "conditions under which group members are better able to conduct an unbiased assessment of the information available to them' (p. 337). In support of Hypothesis 5b, I found that this confirmation bias was lessened in groups containing a minority opinion. The presence of a minority may encourage people to consider multiple viewpoints and engage in divergent thinking (De Dreu \& De Vries, 1996; Nemeth, 1986; Nemeth \& Rogers, 1996). Therefore, in groups containing a minority, group members may have been more open to information contrary to their opinion. SchulzHardt et al. (2002) found that the presence of an opinion minority lowered group confidence, as members may come to question their opinion in the light of dissent. This lower confidence may make group members more open to information contrary to their viewpoint because group members are more willing to consider that their viewpoint may not be ideal.

Another possibility for the reduced confirmation bias is that groups containing an opinion minority develop different norms than consensus groups. Postmes, Spears, and Cihangir (2001) investigated groups with norms for consensus and norms for critical thought. They found that groups with norms for critical thought were more open than consensus norm groups to new information that challenged many of the group members' pre-group opinions. Although Postmes et al. (2001) manipulated group norms through prior group experience, it is possible that the presence of a dissenting opinion minority could decrease the presence of consensus norms within a group and promote more critical thought. However, group norms were not measured in the present study, nor was confidence in the group. Therefore, I am unable to study why the presence of an opinion minority lowered the confirmation bias. However, these potential explanations offer a fruitful area for future research.

\section{Minority versus majority members}

Finally, in groups containing an opinion minority, the minority was compared to the majority group members. Minorities were more open to other's unshared information and information not supporting their opinion than the majority members. Minorities rated other's unshared information and information against their opinion as more important than the majority members did. Further, they were more open to information supporting the group opinion when they did not prevail. Minority members may have considered other's information and information against their opinion as more important than the majority members did because of lower confidence. Learning that they are the minority opinion in the group may make minority members second guess their opinion and lower their confidence in their views. Schultz-Hardt et al. (2002) state that learning that others chose another alternative may signal to a group member that he or she is incorrect. Participants with high confidence may not seek out additional information because their confidence is sufficiently high that they do not think their decisions have to be evaluated any more. However, a member with lower confidence may be more open to new information, as they evaluate more alternatives or seek additional information to bolster their confidence. Therefore, upon learning that most people disagree with them, minority members may become less confident and more willing to ascribe importance to information from other members and information against their opinion. Minority members also rated shared information they mentioned as less important than majority members. Because of their position, minority members may receive less social validation when they mention information than majority members. Therefore, because the information they mention is not received as well, it might have diminished importance.

\section{Future research}

This study examined how individuals perceived the importance of information after a group discussion. Future research should examine some of the variables that may mediate the 
results found in this paper. For example, it was proposed that confidence or group norms may mediate the lowered confirmation bias in minority-containing groups. Neither of these was measured, but they are interesting variables to pursue in further research. Also, future research may want to examine if minority members receive less social validation during the group discussion and if this is related to the lowered importance minority members attribute to the information they mention.

Other research should use group sizes larger than three. A minority of one may be less effective at lessening the confirmation bias in larger groups, or a minority of two or more group members in a larger group may have a stronger effect. Further, as the group size increases, a larger number of group members have the shared information, and therefore, it should receive more validation, increasing its importance compared to unshared information. Finally, researchers may want to examine the differences in mutual enhancement when one mentions shared information oneself versus when another group member mentions the shared information. Is hearing another mention shared information more validating, as my results suggested?

In conclusion, this study aimed to understand individual level processes that may underlie the bias groups have for shared information. Specifically, I examined several variables that could affect the perceived importance of shared information after a group discussion. I found that shared information other group members mentioned and information confirming one's view was rated as more important. This suggests that shared information would be rated as especially important in hidden profile type situations, where the shared information supports group member's initial decision. Further, shared information may dominate in the group because group members hear other members mentioning it. I did not find that repetition or ownership of information increases its importance. However, this is the first study examining the common information bias and investigating ownership and repetition of information that has tracked the discussion of information to its rated importance.
The failure of these variables to affect the rated importance of information in this study should not exclude them from future research. Finally, the presence of a minority proved to be an important variable. The presence of a minority member decreased the confirmation bias, and minority members rated information against their individual viewpoint and other's unshared information as more important, suggesting that minority members may be more open to additional information. Further, minorities actually rated information they mentioned as less important than information they did not mention, suggesting that their information may not have been well received in the group. These results suggest that, in addition to group processes in information exchange, researchers should pay attention to how individual's perception of the information changes as a result of how the information is discussed by the group.

\section{Acknowledgments}

Special thanks to Emily Seinfeld, Tracy Thau, Cara Ludutsky, Matt Hollingshead, Carri Leto, Suzi Sutton, Anne Kramer, Oana Eftimie, and Tessa Rohde for assistance with data collection and coding. Part of this paper was presented at the 2004 International Communication Association conference in New Orleans, LA. This research was supported by a grant from the Dispute Resolution Research Center at Kellogg School of Management, Northwestern University.

\section{References}

Alba, J. W., Chromiak, W., Hasher, L., \& Attig, M. S. (1980). Automatic encoding of category size information. Journal of Experimental Psychology: Human Learning and Memory, 6, 370-378.

Alicke, M. D., Klotz, M. L., Breitenbecher, D. L., Yurak, T. J., \& Vrendenburg, D. S. (1995). Personal contact, individuation, and the betterthan-average effect. Journal of Personality and Social Psychology, 68, 804-825.

Arkes, H. L. (1993). Some practical judgment and decision-making research. In N. J. Castellan, Jr. (Ed.), Individual and group decision making: Current issues. (pp. 3-18). Hillsdale, NJ: Erlbaum. 
Boehm, L. E. (1994). The validity effect: A search for mediating variables. Personality and Social Psychology Bullettin, 20, 285-293.

Brodbeck, F. C., Kerschreiter, R., Mojzisch, A., Frey, D., \& Schulz-Hardt, S. (2002). The dissemination of critical unshared information in decisionmaking groups: The effect of prediscussion dissent. European Journal of Social Psychology, 32, 35-56.

Bryk, A. S., \& Raudenbush, S. W. (1992). Hierarchical linear models: Applications and data analysis methods. Newbury Park, CA: Sage.

Chernyshenko, O. S., Miner, A. G., Baumann, M. R., \& Sniezek, J. A. (2003). The impact of information distribution and group discussion on member judgment: The differential cue weighting model. Organizational Behavior and Human Decision Processes, 91, 12-25.

Cruz, M. G., Boster, F. J., \& Rodriguez, J. I. (1997). The impact of group size and proportion of shared information on the exchange and intergration of information in groups. Communication Research, 24, 291-313.

De Dreu, C. K. W., \& De Vries, N. K. (1996). Differential processing and attitude change following majority versus minority arguments. British Journal of Social Psychology, 35, 77-90.

Dennis, A. R. (1996). Information exchange and use in small group decision making. Small Group Research, 27, 532-550.

Frey, D. (1986). Recent research on selective exposure to information. In L. Berkowitz (Ed.), Advances in experimental social psychology (Vol. 19, pp. 41-80). New York: Academic Press.

Gigone, D., \& Hastie, R. (1993) The common knowledge effect: Information sharing and group judgment. Journal of Personality and Social Psychology, 65, 959-974.

Gigone, D., \& Hastie, R. (1997). The impact of information on small group choice. Journal of Personality and Social Psychology, 72, 132-140.

Greitemeyer, T., \& Schulz-Hardt, S. (2003). Preference-consistent evaluation of information in the hidden profile paradigm: Beyond group-level explanations for the dominance of shared information in group decisions. Journal of Personality and Social Psychology, 84, 322-339.

Gruenfeld, D. H., Mannix, E. A., Williams, K. Y., \& Neale, M. A. (1996). Group composition and decision-making: How member familiarity and information distribution affect process and performance. Organizational Behavior and Human Decision Processes, 67, 1-15.
Guetzkow, H. (1950). Unitizing and categorizing problems in coding qualitative data. Journal of Clinical Psychology, 6, 47-58.

Hasher, L., \& Chromiak, W. (1977). The processing of frequency information: An automatic mechanism? Journal of Verbal Learning and Verbal Behavior, 16, 173-184.

Hasher, L., Goldstein, D., \& Toppino, T. (1977). Frequency and the conference of referential validity. Journal of Verbal Learning and Verbal Behavior, 16, 107-112.

Hasher, L., \& Zacks, R. T. (1984). Automatic processing of fundamental information: The case of frequency of occurrence. American Psychologist, 39, 1372-1388.

Henningsen, D. D., \& Henningsen, M. L. M. (2003). Examining social influence in information-sharing contexts. Small Group Research, 34, 391-412.

Hertwig, R., Gigerenzer, G., \& Hoffrage, U. (1997). The reiteration effect in hindsight bias. Psychological Behavior, 104, 194-202.

Hollingshead, A. B. (1996a). Information suppression and status persistence in group decision making: The effects of communication media. Human Communications Research, 23, 193-219.

Hollingshead, A. B. (1996b). The rank-order effect in group decision making. Organizational Behavior and Human Decision Processes, 68, 181-193.

Kahneman, D., Knetsch, J. L., \& Thaler, R. H. (1991). Anomalies: The endowment effect, loss aversion, and the status quo bias. Journal of Economic Perspectives, 5, 193-206.

Larson, J. R., Jr., Christensen, C., Abbott, A. S., \& Franz, T. M. (1996). Diagnosing groups: Charting the flow of information in medical decision-making teams. Journal of Personality and Social Psychology, 71, 315-330.

Larson, J. R. Jr., Foster-Fishman, P. G., \& Franz, T. M. (1998). Leadership style and the discussion of shared and unshared information in decision-making groups. Personality and Social Psychology Bulletin, 24, 482-495.

Larson, J. R., Jr., Foster-Fishman, P. G., \& Keys, C. B. (1994). The discussion of shared and unshared information in decision-making groups. Journal of Personality and Social Psychology, 67, 446-461.

Lord, C. G., Ross, L., \& Lepper, M. R. (1979). Biases assimilation and attitude polarization: The effects of prior theories on subsequently considered evidence. Journal of Personality and Social Psychology, 37, 2098-2109. 
Meyers, R.A., Brashers, D.E., \& Hanner, J. (2000). Majority-minority influence: Identifying argumentative patterns and predicting argument-outcome links. Journal of Communication, 50, 3-30.

Moscovici, S. (1980). Toward a theory of conversion behavior. In L. Berkowitz (Ed.), Advances in experimental social psychology (Vol. 13). New York: Academic Press.

Nemeth, C. J. (1986). Differential contributions of majority and minority influence. Psychological Review, 93, 23-32.

Nemeth, C. J., \& Rogers, J. (1996). Dissent and the search for information. British Journal of Social Psychology, 35, 67-76.

Nezlek, J. B. (2001). Multilevel random coefficient analyses of event- and interval-contingent data in social and personality psychology research. Personality and Social Psychology Bulletin, 27, 771-785.

Parks, C. D., \& Cowlin , R. A. (1996). Acceptance of uncommon information into group discussion when that information is or is not demonstrable. Organizational Behavior and Human Decision Processes, 66, 307-315.

Postmes, T., Spears, R., \& Cihangir, S. (2001). Quality of decision making and group norms. Journal of Personality and Social Psychology, 80, 918-930.

Propp, K. M. (1997). Information utilization in small group decision making: A study of the evaluative interaction model. Small Group Research, 28, 424-453.

Russo, J. E., Medvec, V. H., \& Meloy, M. G. (1996). The distortion of information during decisions. Organizational Behavior and Human Decision Processes, 66, 102-110.

Savadori, L., Van Swol, L. M., \& Sniezek, J. A. (2001). Information sampling and confidence within groups and judge advisor systems. Communication Research, 28, 737-771.

Schittekatte, M., \& Van Hiel, A. (1996). Effects of partially shared information and awareness of unshared information on information sampling. Small Group Research, 27, 431-449.

Schulz-Hardt, S., Frey, D., Lüthgens, C, \& Moscovici, S. (2000). Biased information search in group decision making. Journal of Personality and Social Psychology, 78, 655-669.

Schulz-Hardt, S., Jochims, M., \& Frey, D. (2002). Productive conflict in group decision making: Genuine and contrived dissent as strategies to counteract biased information seeking.
Organizational Behavior and Human Decision Processes, 88, 563-586.

Stasser, G., \& Stewart, D. (1992). Discovery of hidden profiles by decision-making groups: Solving a problem versus making a judgment. Journal of Personality and Social Psychology, 63, 426-434.

Stasser, G., Stewart, D. D., \& Wittenbaum, G. M. (1995). Expert roles and information exchange during discussion: The importance of knowing who knows what. Journal of Experimental Social Psychology, 31, 244-265.

Stasser, G., Taylor, L. A., \& Hanna, C. (1989). Information sampling in structured and unstructured discussions of three- and sixperson groups. Journal of Personality and Social Psychology, 57, 67-78.

Stasser, G., \& Titus, W. (1985). Pooling of unshared information in group decision making: Biased information sampling during discussion. Journal of Personality and Social Psychology, 48, 1467-1478.

Stasser, G., \& Titus, W. (1987). Effects of information load and percentage of shared information on the dissemination of unshared information during group discussion. Journal of Personality and Social Psychology, 53, 81-93.

Stewart, D. D. (1998). Stereotypes, negativity bias, and the discussion of unshared information in decision-making groups. Small Group Research, 29, 643-668.

Stewart, D. D., Billings, R. S., \& Stasser, G. (1998). Accountability and the discussion of unshared, critical information in decision-making groups. Group Dynamics 2, 18-23.

Stewart, D. D., \& Stasser, G. (1995). Expert role assignment and information sampling during collective recall and decision making. Journal of Personality and Social Psychology, 69, 619-628.

Surowiecki, J. (2004). The wisdom of crowds: Why the many are smarter than the few and how collective wisdom shapes business, economies, societies, and nations. New York: Doubleday.

Tindale, R. S., \& Kameda, T. (2000). 'Social sharedness' as a unifying theme for information processing in groups. Group Processes $\mathcal{E}$ Intergroup Relations, 3, 123-140.

Van Hiel, A., \& Schittekatte, M. (1998). Information exchange in context: Effects of gender composition of group, accountability, and intergroup perception on group decision making. Journal of Applied Social Psychology, 28, 2049-2067.

Van Swol, L. M., Savadori, L., \& Sniezek, J. A. (2003). Factors that may affect the difficulty of 
uncovering hidden profiles. Group Processes $\mathcal{E}^{\circ}$ Intergroup Relations, 6, 285-304.

Van Swol, L. M., \& Sniezek, J. A. (2002, May). Trust me, I'm an expert: Trust and confidence in the acceptance of expert advice. Presented at the Behavioral Decision Research in Management Conference, Chicago, IL.

Wittenbaum, G. M. (1998). Information sampling in decision-making groups: The impact of members' task relevant status. Small Group Research, 29, 57-84.

Wittenbaum, G. M., \& Bowman, J. M. (2004). A social validation explanation for mutual enhancement. Journal of Experimental Social Psychology, 40, 169-184.

Wittenbaum, G. M., Hubbell, A. P., \& Zuckerman, C. (1999). Mutual enhancement: Toward an understanding of the collective preference for shared information. Journal of Personality and Social Psychology, 77, 967-978.

Wittenbaum, G. M., \& Stasser, G.S. (1996). Management of information in small groups. In J.L. Nye \& A.M. Brower (Eds.), What's social about social cognition? Research on socially shared cognition in small groups (pp. 3-28). Thousand Oaks, CA: Sage.

Wood, W., Lundgren, S., Ouellette, J. A., Busceme, S., \& Blackstone, T. (1994). Minority influence: A meta-analytic review of social influence processes. Psychological Bulletin, 115, 323-345.

Yaniv, I., \& Kleinberger, E. (2000). Advice taking in decision making: Egocentric discounting and reputation formation. Organizational Behavior and Human Decision Processes, 83, 260-281.

Paper received 12 January 2005; revised version accepted 25 June 2005.

\section{Biographical note}

LYN M. VAN SWOL is an assistant professor of communication studies at Northwestern University. Her PhD is in social psychology from the University of Illinois at Urbana-Champaign. Her research interests include information sharing in groups, advice giving, nonverbal interaction in groups, and trust in advisors. 